\title{
Impressões sobre segurança: Perspectiva dos soteropolitanos em relação à segurança dos seus bairros
}

\author{
Tânia Benevides ${ }^{1}$, Aline Pauliana Lima1', Lavinia Santos', Angélica \\ Olímpia Santos ${ }^{2}$, José Flávio Passos ${ }^{3}$ e Victor Said ${ }^{3}$ \\ ${ }^{1}$ Departamento de Ciências Humanas da Universidade do Estado da Bahia, Brasil | \\ tbenevides@uneb.com.br; paulianasf87@gmail.com; laviniass22@gmail.com | \\ https://orcid.org/0000-0001-9191-7831; http://orcid.org/0000-0002-0129-5950; \\ https://orcid.org/0000-0001-8416-7761 \\ Escola de Administração da Universidade Federal da Bahia, Brasil | \\ angelicaolimpia@hotmail.com I https://orcid.org/0000-0001-5243-9638 \\ ${ }^{3}$ Departamento de Ciências Humanas da Universidade do Estado da Bahia, Brasil I \\ faopassos@gmail.com; 231610248@uneb.br I https://orcid.org/0000-0001-8498-8383; \\ https://orcid.org/0000-0002-4761-5227
}

Resumo: Este artigo busca analisar a percepção dos moradores da cidade de Salvador capital do Estado da Bahia, no Brasil, em relação aos elementos que podem promover maior segurança aos 163 bairros da capital baiana. O estudo parte da seguinte questão de investigação: qual a percepção dos soteropolitanos em relação aos fatores que podem trazer mais segurança para o seu bairro? O objetivo geral é analisar as impressões dos moradores de Salvador quanto aos elementos que podem levar ao aumento da segurança nos seus respectivos bairros. Para alcançar este objetivo, o percurso metodológico baseia-se numa pesquisa qualitativa, iniciada a partir de uma fase exploratória, elaborada a partir da pesquisa bibliográfica e documental, seguida da pesquisa de campo, através da aplicação do instrumento de coleta de dados, que resultou na aplicação de 15.260 questionários em todos os bairros da capital, entre os anos de 2018 e 2020. Este estudo é um recorte de uma pesquisa mais ampla, realizada por um grupo de pesquisadores que integram um projeto maior denominado QUALISalvador, que se dedica a produzir e difundir conhecimento sobre a realidade de Salvador. O recorte deste artigo é a questão 56 "O que poderia trazer segurança para seu bairro?" do referido questionário. Os dados utilizados nesta análise derivam dos estudos realizados pelo subgrupo que avalia a influência da segurança pública e a percepção de segurança/insegurança dos moradores. Como principal resultado ficou evidente que, na percepção dos soteropolitanos, o que poderia trazer mais segurança aos seus bairros, é o aumento das ações do Estado, através do policiamento ostensivo e de rondas nos bairros. A partir deste resultado, pode-se refletir sobre o impacto da atuação repreensiva do Estado, levando à reflexão sobre os aspectos intersetoriais da segurança, que vão muito além da ação policial, assegurando, inclusive, o direito à cidade e a garantia dos direitos fundamentais

Palavras-chave: Cidade; Direito à cidade; Segurança Urbana; Segurança Pública; QUALISalvador.

Impressions about Security: Salvador Residents Perspective in Relation to their Neighborhoods Security

Abstract: This article seeks to analyze the perception of the Salvador City residents, Bahia State Capital, in Brazil, in relation to the elements that can promote the biggest security to the 163 Bahia Capital neighborhoods. The study starts from the research question: what is the Salvador residents' perception in relation to the factors that can bring more security to their neighborhood? The general objective is to analyze the Salvador inhabitant's impressions as elements that can lead to increased security in their respective neighborhoods. To achieve this objective, the methodological path is based on a qualitative research, initiated from an exploratory phase, elaborated from the bibliographic and documentary research, followed by the field research, through the application of the data collection instrument, which resulted in the application of 15,260 questionnaires in all neighborhoods of the capital, between the years 2018 and 2020. This study is part of a broader survey, carried out by a group of researchers who are part of a larger project called QUALISalvador, whose objective is to produce and disseminate knowledge about the reality of Salvador. The clipping of this article is the question 56 "What could bring security to your neighborhood?" of the questionnaire. The data used in this analysis are derived from studies carried out by the subgroup that assesses the influence of public security and the residents' perception of security / insecurity. As a main result, it was evident that, in the perception of the Salvadorans, what could bring more security to their neighborhoods is the increase in State actions, through ostensive policing and rounds in the neighborhoods. Based on this result, it is possible to reflect on the impact of the State's reprehensible performance, leading to reflection on the intersectoral aspects of security, which go far beyond police action, ensuring, even, the right to the city and the guarantee of fundamental rights.

Keywords: City; City's right; Urban Security; Public security; QUALISalvador. 


\section{Introdução}

Uma cidade segura tem como premissa um espaço urbano que seja planejado e inclusivo, de modo a atender às necessidades de seus moradores e fornecendo condições de igualdade para o exercício da cidadania. Logo, quando se tem exclusão social, ela se expressa na formatação do espaço urbano. Quando esse espaço cresce de forma desenfreada e, por vezes, desamparada das autoridades públicas, há uma crescente desintegração socioterritorial. As comunidades menos privilegiadas passam a sofrer com carência de serviços essenciais, abrindo espaço para o surgimento do crime organizado e da violência dele provida. A omissão do poder público permite que essas organizações criminosas ocupem o comando que deveria ser do Estado (Carbonari \& Lima, 2016), negando direitos fundamentais à parte da população.

A realidade urbana é influenciada por fatores como raça, gênero e renda, a "Exclusão, segregação, informalidade e ilegalidade são realidades enfrentadas por parte dos moradores das cidades brasileiras e dos países em desenvolvimento" (Amanajás \& Klug, 2018 , p. 30). O reconhecimento do direito à cidade, portanto, encontra-se em ruptura quando analisamos a vivência urbana brasileira.

Este artigo parte da seguinte questão de investigação: Qual a percepção dos moradores da cidade de Salvador em relação aos fatores que podem trazer mais segurança para o seu bairro? O objetivo geral é analisar as impressões dos soteropolitanos quanto aos elementos que podem promover maior segurança para seus respectivos bairros. Para isso, os objetivos específicos são: identificar fatores que influenciem na percepção de segurança/insegurança na escala bairro; e identificar, na visão dos moradores, quais fatores trariam maior segurança aos bairros analisados.

$O$ artigo divide-se em cinco seções. A primeira é a introdução, a segunda promove breve reflexão sobre segurança e violência no contexto urbano. A terceira apresenta a metodologia. A quarta debate se a segurança urbana é um caminho possível na cidade de Salvador. A última aborda as considerações finais.

\section{Segurança e Violência no Contexto Urbano}

Historicamente, a cidade ocidental representava um espaço de integração social e cultural - um lugar seguro e protegido da violência, um espaço que viabilizava o intercâmbio de conhecimentos, pessoas e cultura. Contudo, a cidade também se tornou local de referência de distinção e de separação; de marginalização e de exclusão. Há uma reorganização do espaço urbano que envolve uma redução das interseções entre a vida dos ricos e a dos pobres, o que transcende a segregação social e a fragmentação urbana tradicional (Davis, 2008; Secchi, 2020).

O desenvolvimento de uma cultura de violência e medo na urbe poderia explicar a multiplicação das violências, que se acentua em determinados territórios, apesar das inúmeras ações policiais. Entretanto, as questões relacionadas às violências urbanas estão, para além das estatísticas, também vinculadas à discriminação, à gestão e qualificação do efetivo policial, às preocupações eleitoreiras, aos interesses comerciais e à governança da segurança urbana - sendo, portanto, multifatorial. É preciso reconhecer que a segurança e a insegurança não são simples condições objetivas (Crettiez, 2011; Gledhill et al., 2017; Haesbaert, 2018; Soares, 2021).

Ainda que o desenvolvimento urbano desigual seja efetivamente um fator que fomenta e amplia o conflito social, e entendendo que a percepção da violência ganhe diferentes contornos nos diferentes contextos urbanos, Harvey (2013) chama a atenção para o fato de que as cidades nunca foram lugares harmoniosos, sem confusão, conflito ou violência. A sensação de insegurança na cidade é, principalmente, fruto do desequilíbrio estrutural imposto pelo modo de produção vigente. 
A sensação de medo ou tranquilidade, como afirma Soares (2019, p. 56), “... deriva da percepção que temos de nossas interações, do contexto em que nos situamos e das circunstâncias ao redor de nós mesmos e das pessoas significativas para nós", que pode levar à repulsa ou à aproximação entre os sujeitos. A ignorância e o medo nos preenchem de sentimentos negativos em relação ao "outro" e ao espaço urbano, isto porque a diversidade e a diferença, no contexto de vulnerabilidade e desigualdade social, podem desenvolver comportamentos de intolerância e segregação, levando à marginalidade e exclusão dos "outros", podendo levar até ao confronto (Harvey, 2013).

Nesse sentido, a repulsa entre os sujeitos é reforçada pelos meios de comunicação de massa, que cumprem um papel oportuno - e muitas vezes questionável - enquanto agentes que não só colaboram, mas também potencializam os medos e os estigmas entorno da segurança pública, "... a mídia opera como importante elo na cadeia das desiguais produções narrativas, concorrendo para a formação diferenciada de expectativas ..." (Soares, 2019, p. 120). Reforçam-se, sobremaneira, duas sensações "instaladas" na população: medo e naturalização das estatísticas sobre a violência.

Como afirma Gehl (2013, p. 91), uma cidade segura é aquela que permite às pessoas abraçarem o espaço urbano, "Em geral, a vida e as próprias pessoas tornam a cidade mais convidativa e segura, seja em termos de segurança percebida ou vivenciada". A ordem pública não é assegurada exclusivamente pela polícia - apesar da sua importância -, mas é mantida, fundamentalmente, pela rede imbricada de controles e padrões de comportamento presentes no contexto urbano. Certamente, a governança ocupa um importante papel nesta problemática, porém o problema da insegurança não pode ser solucionado pela dispersão das pessoas, mas pela articulação delas (Jacobs, 2011).

As cidades são o locus da reprodução da força de trabalho, entretanto, a melhoria das condições de vida dos sujeitos depende, essencialmente, de uma melhor distribuição de renda e da consolidação de novas e aperfeiçoadas políticas públicas. São as políticas públicas que viabilizam as condições de transporte, moradia, saneamento, educação, saúde, lazer, iluminação pública, coleta de lixo e segurança (Maricato, 2013). No campo da segurança pública, a mera preocupação com a retenção dos índices de criminalidade, centrada na força policial, torna-se insuficiente, fazendo-se necessária uma análise mais estrutural ante uma percepção imediatista para a compreensão do fenômeno urbano.

Deste modo, pode-se compreender que segurança pública é “... a estabilização universalizada, no âmbito de uma sociedade em que vigora o Estado democrático de direito, de expectativas positivas a respeito das interações sociais, ou da sociabilidade, em todas as esferas da experiência individual" (Soares, 2019, p. 119). Para além do conceito, a segurança pública é um campo empírico e organizacional que estrutura e direciona instituições e relações sociais em torno da forma como o Estado regula e administra a ordem e o conflito (Costa \& Lima, 2014).

\section{Metodologia}

Este estudo tem por objetivo produzir e difundir conhecimento sobre a realidade da cidade de Salvador, capital do estado da Bahia e quarta maior capital do Brasil, com população estimada, em 2020, de 2.886.698 habitantes, com PIB, em 2017, de R $\$ 62,7$ bilhões e Índice de Desenvolvimento Humano, em 2010, de 0,759 (Instituto Brasileiro de Geografia e Estatística, 2021). A reflexão aqui desenvolvida tem como referência a pesquisa de campo do Projeto Qualidade do Ambiente Urbano de Salvador (QUALISalvador), que contou com uma amostra de 15.260 questionários, aplicados em domicílios dos 163 bairros da capital, entre 2018 e 2020.

Este artigo busca avaliar as percepções sobre segurança e insegurança dos soteropolitanos. Para tanto, foi aplicado o questionário da pesquisa de campo do projeto QUALISalvador, cuja estrutura contava com 62 questões, sendo 3 delas sobre segurança pública. 
O recorte deste estudo avalia apenas a questão 56 "O que poderia TRAZER SEGURANÇA para seu BAIRRO (marque a alternativa principal)", cujas alternativas eram: Policiamento ostensivo; Efetivo policial; Qualificação dos policiais; Ronda no bairro; Combate ao tráfico de drogas; Ter uma delegacia/posto policial; Investimentos em equipamentos e tecnologia [aparelhamento da polícia]; Valorização e qualificação da força policial; Combate à corrupção policial; Incursões nos redutos do crime; Intensificar blitz nas ruas; Investimentos em infraestrutura no bairro; Investimentos sócio educacionais; Trabalho/ Emprego; Outros; e Não se aplica.

As categorias acima foram elaboradas tendo como referência o Plano Estadual da Segurança Pública (Planesp) de 2012 a 2015, documento que norteia as políticas públicas, planejamento e objetivos estratégicos da segurança pública no estado da Bahia (Secretaria da Segurança Pública, 2011). Utilizou-se a edição do triênio 2012-2015, pois era a versão mais atualizada do documento à época.

No que se refere ao percurso metodológico, este estudo qualitativo iniciou-se com a fase exploratória, por meio da pesquisa bibliográfica e documental (Gil, 2002), seguida da pesquisa de campo (Minayo, 2007), através da aplicação do instrumento de coleta de dados, que foi o questionário, considerado um recurso "neutro" na pesquisa, conforme aponta Triviños (1987). Em seguida, efetuou-se a análise qualitativa dos dados coletados (Minayo, 2007; Triviños, 1987).

Nesse sentido, Minayo (2007) afirma que "são as perguntas que fazemos para a realidade, a partir da teoria que apresentamos e dos conceitos transformados em tópicos de pesquisa que nos fornecerão a grade ou a perspectiva de observação e de compreensão" (Minayo, 2007, p. 76). A partir dos meios de investigação empregados na análise, este estudo se caracteriza pela natureza qualitativa (Triviños, 1987; Minayo, 2007).

\section{A Segurança Urbana: um Caminho Possível para Salvador?}

De acordo com Graham (2016), estima-se que, até $2050,75 \%$ da população mundial residirá em cidades. Com o crescimento urbano acelerado, os problemas urbanos se intensificam. As cidades ordenadas, planejadas de forma mais democrática, oferecem mais segurança, enquanto as cidades desiguais caracterizam-se pela segregação ou ineficiência de serviços públicos, intensa criminalidade e forte presença de agentes de segurança, impactando na sensação de segurança e insegurança dos seus habitantes. A desigualdade social e econômica é o alicerce para os altos índices de criminalidade, e as tentativas privadas de proteção à vida e à propriedade - arames farpados, grades, segurança privada, enclaves fechados, entre outras - não vão resolver essa problemática (Graham, 2016).

$\mathrm{Na}$ impressão dos soteropolitanos, quando questionados sobre o que poderia trazer maior segurança aos bairros da capital, há uma convergência ao indicar a ação do Estado como um dos principais meios de promoção da seguridade. Conforme ilustra a Fig. 1, a pesquisa de campo revelou que $21,51 \%$ dos moradores de Salvador apontam o policiamento ostensivo como principal solução para a questão da segurança nos bairros da capital baiana, $19,10 \%$ acredita que a solução seria a ampliação de rondas nos bairros e $11,46 \%$ indicam os investimentos socioeducacionais. 


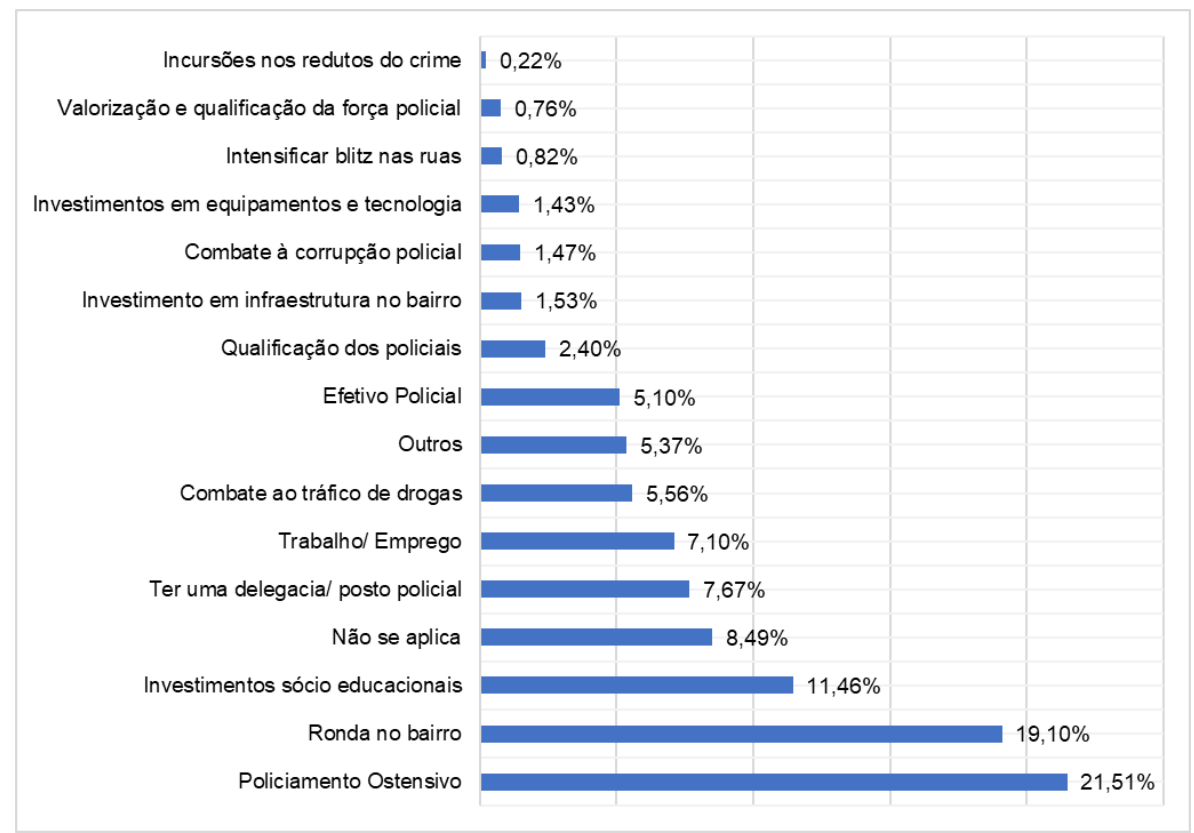

Fig. 1. Fatores condicionantes da segurança para os moradores de Salvador

Observa-se que, apesar de não apontar neste trabalho as diferenças em termos socioeconômicos e de infraestrutura entre bairros, é o policiamento que aparece como prérequisito para a segurança do seu bairro na percepção dos moradores da cidade de Salvador. O fator "investimento em infraestrutura no bairro" - que poderia melhorar a pavimentação, a iluminação, e os equipamentos urbanos, entre outros elementos, resultando na ampliação da movimentação da área requalificada -, aparece apenas em $1,43 \%$ das escolhas dos respondentes. Assim, podemos aferir que, para a população de Salvador, os fatores mais relevantes para a promoção de segurança na cidade estão relacionados ao emprego da força policial.

Cabe, então, avaliar se o policiamento seria um recurso capaz de trazer segurança para Salvador. Talvez a resposta fosse positiva na concepção dos moradores, mas essa é uma concepção influenciada por uma compreensão estreita. Cano (2006), ao falar das políticas de segurança pública no Brasil e das tentativas de modernização e democratização versus a guerra contra o crime ou dos interesses que fundamentam a securitização da vida urbana, aponta que a população brasileira tem de fato uma visão estreita sobre os recursos ou fatores que são capazes de trazer segurança.

Apesar da percepção dos moradores pelo policiamento ostensivo, a centralidade da redução nos níveis de insegurança, violência e medo está nos investimentos em segurança urbana, pois as cidades precisam ser planejadas e desenvolvidas para que se tornem vivas, seguras, sustentáveis e saudáveis, reforçando sua função social, funcionando como locais de encontro e contribuindo para a construção de uma sociedade inclusiva e democrática.

De acordo com Carbonari e Lima (2016), cabe ao Estado desenvolver políticas de prevenção da violência, sendo esse um tema intersetorial, para além da segurança pública e da ação policial. Isso porque o combate à violência não se dá apenas por meio da repressão, mas também pelos meios de prevenção. Os fatores que influenciam a segurança urbana são apresentados na Fig. 2, conforme Gehl (2013), e devem servir de referência para pensar a segurança urbana em Salvador. 


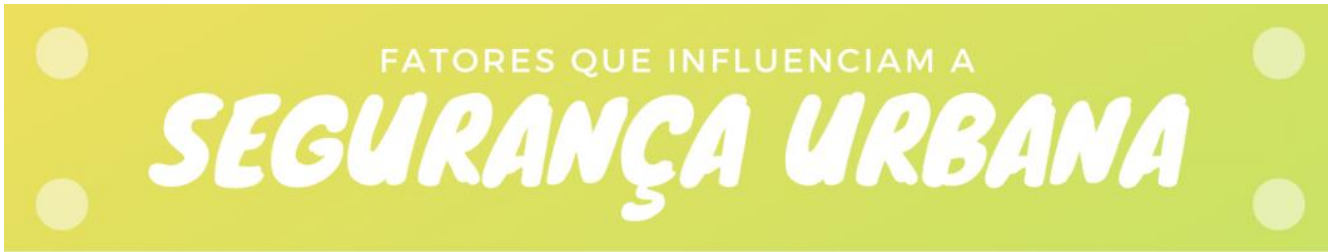

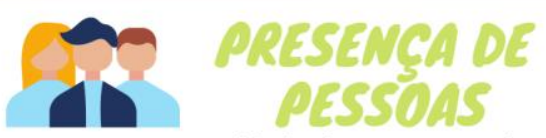

Pessoas tornam a cidade viva, geram movimento no espaço urbano e perpassam a sensação de segurança. Isso pode ser estimulado através de condições propícias à permanência no espaço público.

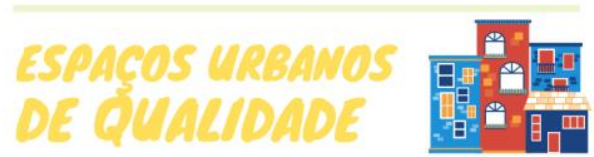

Espaços públicos bons e convidativos para serem utilizados pela população. Através de ruas pavimentadas, parques públicos, praças, pontes e outros locais em bom estado de conservação.

\section{TRÁFEGO}

Trânsito democrático e seguro, priorizando a segurança dos pedestres. Utilização de placas. sinalizações e vias para organização do tráfego, estimulando diferentes tipos de transportes como bicicletas, metrô e coletivos.
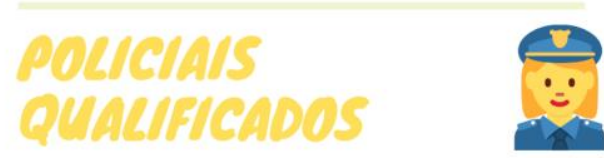

Fundamentais para preservação da ordem pública. São necessários treinamentos e capacitações além de boas condições para o serviço.

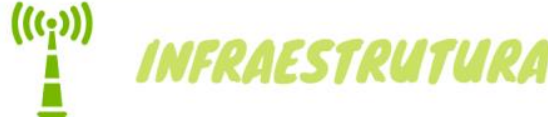

Conjunto de serviços básicos indispensáveis para o bom funcionamento de uma cidade ou sociedade. Como rede de água, telefone, internet, energia e saneamento.

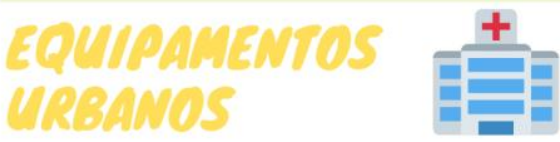

Bens de utilidade pública, destinados à prestação de serviços necessários ao funcionamento da cidade. São exemplos: escolas, postos policiais, hospitais, creches e transporte coletivo.

$\approx$

\section{J ATIVIDADES SOCIAIS}

Ações promovidas por entidades públicas e/ou privadas para estimular movimentos socioculturais e proporcionar entretenimento a população. Através de praças, academias ao ar livre, quadras, campos de esportes, teatro etc.

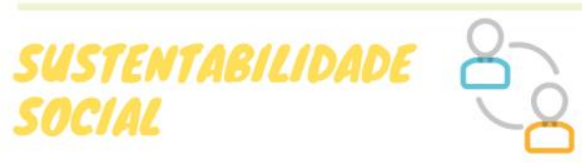

Melhora a qualidade de vida, reduz a desigualdade social e integra diferentes grupos sociais, de maneira democrática e acessivel.

Fig. 2. Fatores que influenciam na segurança urbana.

Nessa perspectiva, a cidade para os soteropolitanos pode ser compreendida como um espaço plural, capaz de comportar a diversidade de pessoas, o respeito e a tolerância aos "outros", sendo ainda um espaço de manifestações sociais que assegure o direito à cidade para todos. O papel do Estado, portanto, não é apenas o de garantir o exercício da força policial, mas também o de assegurar o desenvolvimento de políticas públicas que promovam a segurança do cidadão.

\section{Considerações Finais}

A segurança urbana é, então, um caminho possível? Salvador, como tantas outras cidades, tem se constituído em um recurso, em objeto per se, de acumulação de capital e de poder. Nesse projeto, o pleno direito de usufruto à cidade restringe-se dia após dia. 
No que concerne aos fatores que influenciem a percepção de segurança/insegurança na escala bairro, foram identificados 14 fatores baseados no Planesp, que foram utilizados como elementos de comparação pelo subgrupo dedicado ao estudo da segurança pública do QUALISalvador.

Ao buscar compreender as impressões dos moradores da cidade de Salvador em relação aos fatores que poderiam trazer mais segurança para os bairros da cidade, ficou evidenciado que a população ainda atribui ao policiamento maior relevância em detrimento dos investimentos em infraestrutura no bairro. Assim, foi possível notar que as respostas obtidas através da pesquisa de campo, evidenciaram que, para os moradores de Salvador, o que pode levar à promoção de maior segurança nos seus respectivos bairros são, principalmente: policiamento ostensivo $(21,51 \%)$ e ronda no bairro $(19,10 \%)$.

Para uma cidade ser considerada segura, além da ação policial e do Estado, conforme discutido, é necessário que haja inclusão social, garantindo o pleno direito de a população exercer sua cidadania. É imprescindível ponderar sobre os mais diversos aspectos da vida quando tratamos de segurança, entendendo a complexidade deste tema e sua natureza multifatorial. Sendo possível a garantia dos direitos fundamentais e ampla participação da vida citadina, inclusive no que concerne à realidade de Salvador.

\section{Agradecimentos}

Às instituições financiadoras do Projeto QUALISalvador: Fundação de Amparo à Pesquisa do Estado da Bahia (FAPESB) e Empresa Baiana de Águas e Saneamento S.A. (EMBASA), e às instituições: Universidade Federal da Bahia, Universidade do Estado da Bahia e Universidade Estadual de Feira de Santana.

\section{Referências}

Amanajás, R., \& Klug, L. (2018). Direito à cidade, cidade para todos e estrutura sociocultural urbana. In M. A. Costa, C. B. Favarão \& M. T. Q. Magalhães (Orgs.), A nova agenda urbana e o Brasil: Insumos para sua construção e desafios a sua implementação (pp. 29-43). IPEA.

Cano, I. (2006). Políticas de segurança pública no Brasil: tentativas de modernização e democratização versus a guerra contra o crime. Sur. Revista Internacional de Direitos Humanos, 3(5), 136-155.

Carbonari, F., \& Lima, R. S. (2016). Cidades seguras. In M. A. Costa (Org.), O Estatuto da Cidade e a Habitat III: um balanço de quinze anos da política urbana no Brasil e a Nova Agenda Urbana (pp. 85-106). IPEA.

Costa, A. T., \& Lima, R. S. (2014). Segurança pública. In R. S. Lima, J. L. Ratton, \& R. G. Azavedo (Orgs.), Crime, polícia e justiça no Brasil (pp. 482-490). Contexto.

Crettiez, X. (2011). As formas de violência. Loyola.

Davis, M. (2008). Planeta favela. Boitempo.

Gehl, J. (2013). Cidades para pessoas (2ª ed.; A. Marco, Trad.). Perspectiva.

Gil, A. C. (2002) Como elaborar projetos de pesquisa. (4ª ed). Atlas.

Gledhill, J., Hita, M. G., \& Perelman, M. (2017). Introdução a questão urbana, hoje. In J. Gledhill, M. G. Hita, \& M. Perelman (Orgs.), Disputas em torno do espaço urbano: processos de [re] produção/construção e apropriação da cidade (pp. 31-46). Edufba.

Graham, S. (2016). Cidade sitiadas: o novo urbanismo militar (A. Azuma, Trad.). Boitempo.

Haesbaert, R. (2018). Viver no limite: território e multi/transterritorialidade em tempos de insegurança e contenção. Bertrand Brasil.

Harvey, D. (2013). A liberdade da cidade. In D. Harvey, E. et al. Cidades rebeldes: passe livre e as manifestações que tomaram as ruas do Brasil (posição 470-623). Boitempo.

Instituto Brasileiro de Geografia e Estatística (2021). Brasil / Bahia / Salvador. 
Jacobs, J. (2011). Morte e vida das grandes cidades ( $3^{\mathrm{a}}$ ed.). Martins Fontes.

Maricato, E. (2013). É a questão urbana, estúpido! In D. Harvey, E. et al. Cidades rebeldes: passe livre $e$ as manifestações que tomaram as ruas do Brasil (posição 301-468). Boitempo.

Minayo, M. C. S. (2007). Pesquisa Social: Teoria, método e criatividade. (26ª ed.) Editora Vozes.

Secchi, B. (2020). A cidade dos ricos e a cidade dos pobres. Âyiné

Secretaria da Segurança Pública. (2011). Plano Estadual da Segurança Pública PLANESP: Governo da Bahia 2012 a 2015.

Soares, L. E. (2019). Desmilitarizar: segurança pública e direitos humanos. Boitempo.

Soares, L. E. (2021). Violência e segurança pública. Editora PUCRS. 